JOURNAL DE PHYSIQUE IV

Colloque C8, supplément au Journal de Physique III, Volume 6, décembre 1996

\title{
Damping Capacity of Hypo-Eutectic Zn-Al Alloys
}

\author{
T. Kurosawa, T. Otani and K. Hoshino \\ College of Industrial Technology, Nihon University, 1-2-1 Izumi-cho, Narashino, Chiba 275, Japan
}

\begin{abstract}
Damping capacity of hypo-eutectic $\mathrm{Zn}-\mathrm{Al}$ alloys as a function of rolling ratio is investigated. Effect of heat treatment after cold rolling on the damping capacity is discussed. Damping tests were carried out using the method of the free decay of vibrations in bending oscillation. With an increase in rolling reduction, the damping capacity was increased. As the results of tensile and hardness testing show, the elongation was increased and hardness was decreased with an increase in rolling reduction. An increase in the damping capacity indicates higher value for the as rolled alloys with an accompanying work-softening effect. And the increment in the damping capacity by rolling was higher than that of the heat treated alloys. As a results of the microstructural analysis of the alloys, the grains of as rolled alloys were changed to equiaxed structures after a large rolling reduction. And the grains of the heat treated alloy was coarsened during the heat treatment. Tensile testing revealed that the maximum strain rate sensitivity, $m$, was 0.35 for $\mathrm{Zn}-5 \% \mathrm{Al}$ after $85 \%$ rolling reduction.
\end{abstract}

\section{Introduction}

It has been reported that $\mathrm{Zn}-\mathrm{Al}$ alloys show high damping when quenched from above eutectoid temperature, in the range of $\alpha+\beta$ phase. Considerable research of this phenomenon has, therefore, been carried out for rolled or drawn eutectoid alloys by Nutall [1][2] et al. Zn-Al alloys indicate an eutectic formation at about $5 \% \mathrm{Al}$ at a temperature of $655 \mathrm{~K}$, and an eutectoid decomposition at $22 \% \mathrm{Al}$ at a temperature of $548 \mathrm{~K}$. High aluminum $\mathrm{Zn}-\mathrm{Al}$ alloys are advantageous for both higher strength and lower density than those of eutectic alloys. However increasing aluminum content gives a wide temperature range for solidification. This wide solidification temperature range might cause the microshrinkage during solidification. So, many studies were done for hyper-eutectic alloys, especially for $\mathrm{Zn}-22 \% \mathrm{Al}$ eutectoid alloy for its superplastic behaviour. Zinc base alloys were usually used in die casting applications and the effect of rolling to the alloys was not fully investigated. In this study, the internal friction as a function of cold rolling by varying the reduction in area was investigated for binary hypo-eutectic $\mathrm{Zn}-\mathrm{Al}$ alloys with an $\mathrm{Al}$ content in the range from 2 to $5 \% \mathrm{wt}$.

\section{Experimental details}

\subsection{Alloy preparation}

The material used was a zinc alloy of $99.99 \%$, and an aluminum alloy of $99.99 \%$ in purity. Then the specimens were prepared with chemical composition, in wt\%, $\mathrm{Zn}-2-5 \%$ Al which had been melt in a high purity carbon crucible then cast into a metal mold of size $30 \times 160 \times 150 \mathrm{~mm}$. The casting temperature was at the melting point of each chemical composition $+50 \mathrm{~K}$ and the temperature of the mold was $290 \mathrm{~K}$. After the casting, the specimens rolled for $0,25,50$ and $85 \%$ in reduction were prepared. For all Al contents, the specimens were made from the same part of the castings for comparative measurement. Then, specimens with a size of $2 \times 10 \times 150 \mathrm{~mm}$ for the damping test and with a size of $2 \times 10 \times 50 \mathrm{~mm}$ for hardness test were cut from the castings.

\subsection{Damping test and mechanical properties}

Damping test were made for the free decay of vibration in bending oscillation by the impact hammer method schematically illustrated in Fig. 1. These specimen were in air at $293 \mathrm{~K}$. In this measurement, 
the specimen was supported vertically with its bottom edge held fixed and the top end free for vibration.

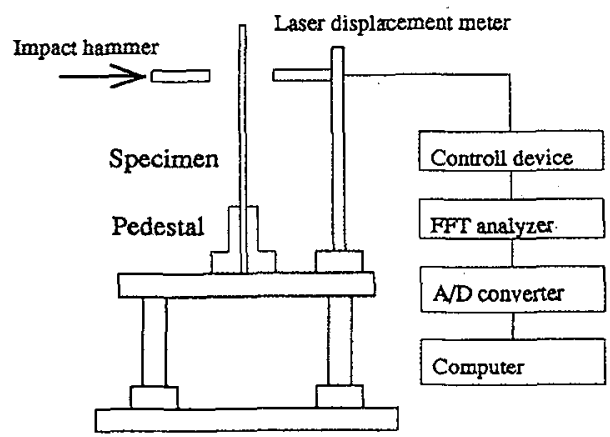

Figure 1: Schematic diagram of the experiment

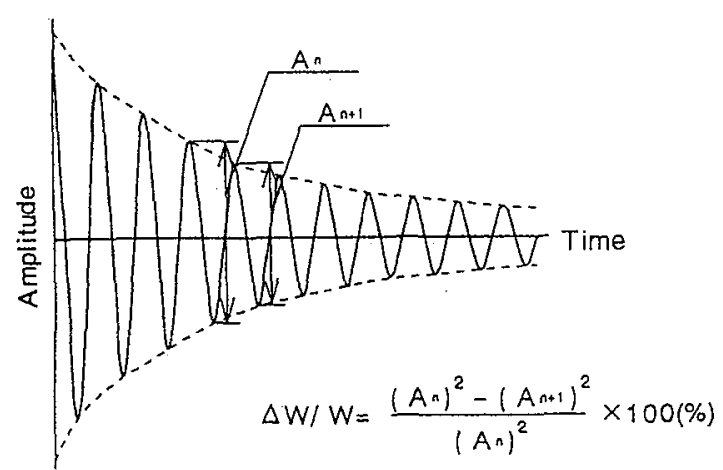

Figure 2: How to obtain a damping capacity

Then the damping capacity $\Delta W / W$ was determined from the free vibration as shown in Fig. 2 . After cold rolling to 25,50 and $85 \%$, one specimen was heat treated at $573 \mathrm{~K}$ for 24 hours followed by a water quench and the others were furnace cooled. Consequently, the damping capacity of the heat treated specimens were measured. Then the hardness was measured under a load of $98.1 \mathrm{~N}$ using a Vickers hardness tester. In tensile tests, the nominal stress $\sigma$ is given by

$$
\sigma=\mathrm{K} \dot{\varepsilon}^{m}
$$

where $\dot{\varepsilon}$ is the strain rate and $m$ is a strain rate sensitivity index. [3]. The strain rate sensitivity was then measured by varying the cross head speeds of $0.5,1,2,4,6,8,10 \mathrm{~mm} / \mathrm{min}$ using a screw drive Instron machine. Then the $m$ value is obtained by the following equation[4]

$$
m=\log \left(\sigma^{\prime} / \sigma\right) / \log \left(\dot{\varepsilon}^{\prime} / \dot{\varepsilon}\right)
$$

where $\dot{\varepsilon}^{\prime}$ is the strain rate at a nominal stress is $\sigma^{\prime}$. These tensile tests were also carried out at a $293 \mathrm{~K}$ in air.

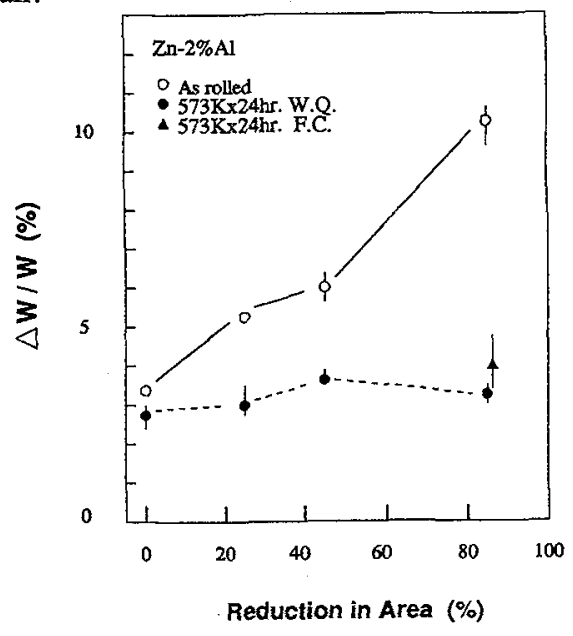

Figure 3: Relation between damping capacity and rolling reduction of $\mathrm{Zn}-2 \% \mathrm{Al}$ alloy

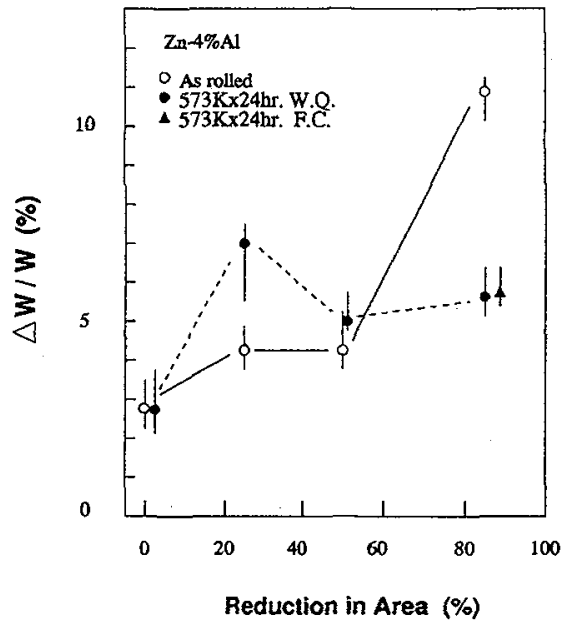

Figure 4: Relation between damping capacity and rolling reduction of $\mathrm{Zn}-4 \% \mathrm{Al}$ alloy 


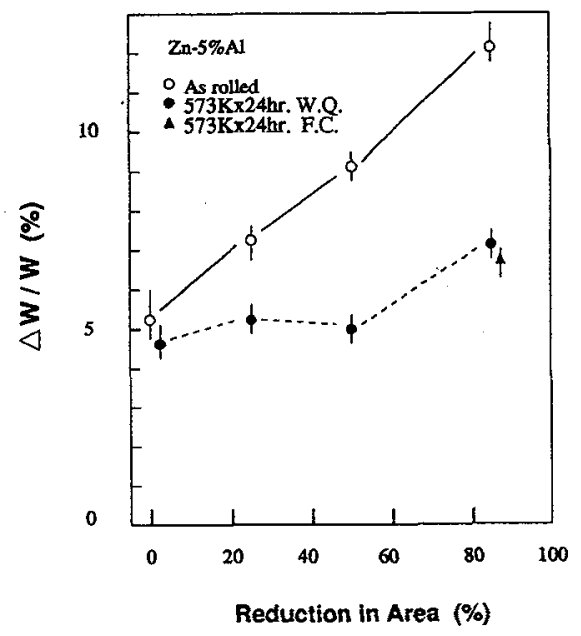

Figure 5: Relation between damping capacity and

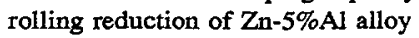

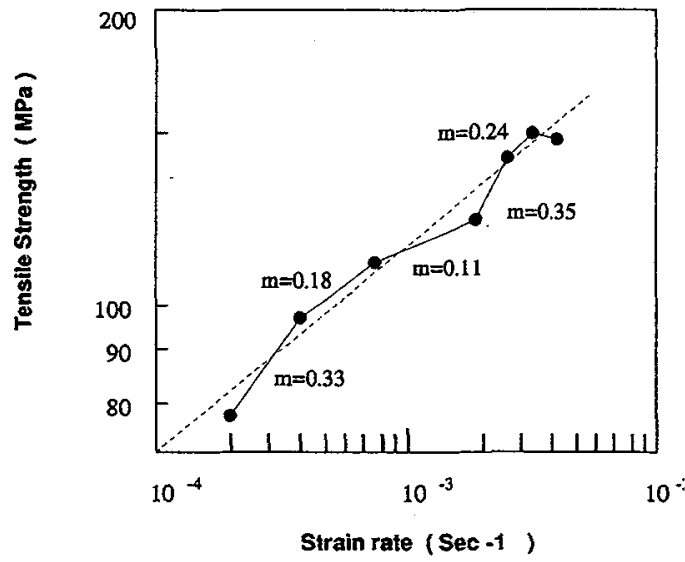

Figure 6: Relation between tensile strength and strain rate of $85 \%$ cold rolled $\mathrm{Zn}-5 \% \mathrm{Al}$ alloy

\section{Results and discussion}

The damping capacity of as cast and heat treated alloys is shown in Fig. 3-5. The measurements were made for the alloys by varying reduction $0,25,50$ and $85 \%$ in area. The damping capacity was gradually increased with an increase in rolling reduction, and shows especially a higher value in the $\mathrm{Zn}-5 \%$ Al alloy with $85 \%$ reduction as shown in Fig. 5. For the as rolled alloys, the increment of the damping capacity by rolling is higher than that of the heat treated ones. The results show that the damping capacity of these cast alloys depends strongly on the rolling reduction. Hence the heat treatment had little influenced on the damping capacity of rolled alloys compared to the effect by rolling. The decrement of hardness of $\mathrm{Zn}-5 \% \mathrm{Al}$ alloy by rolling is greater than that of the heat treated alloy as shown in Fig 7. As can be seen from Fig. 7, hardness was reduced with an increase in rolling reduction and indicated a minimum value of about $35 \mathrm{Hv}$. These results are in good agreement with the microstructure morphology. Microstructures of the alloys are shown in Fig. 8. Considering the effect of

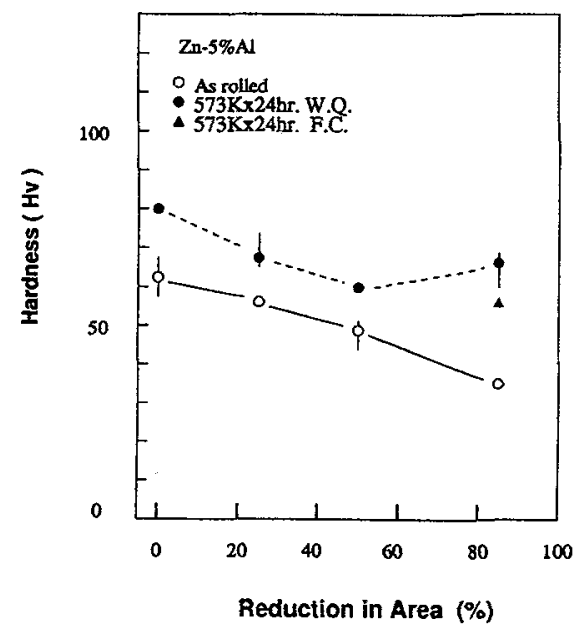
the rolling reduction, the lamellar structure was still remaining under the condition of $50 \%$ reduction. Increasing the rolling reduction up to $85 \%$, these lamellar structure was entirely disappeared to produce an equiaxed fine $\alpha+\beta$ structure approximately the same as that of a quenched sample.[5]. The damping of the polycrystalline alloys, fine equiaxed structure is essentially amplitude-independent previously reported by Ritchie et al. [6,7] and the grain sliding must be a major component. It is reported that, in the condition of superplastic deformation, the $m$ value is higher than $0.3-0.4[8]$. And also reported by Packer et al[9], $\mathrm{Zn}-4.9 \% \mathrm{Al}$ alloy indicated superplasticity with $m=0.5$ in a temperature range from 473 to $633 \mathrm{~K}$. In this experiment, for the $85 \%$ cold rolled $\mathrm{Zn}-5 \% \mathrm{Al}$ alloy, a maximum $m$ value of 0.35 at $293 \mathrm{~K}$ was found with a elongation up to $100 \%$. These $m$ values ranged $0.11-0.35$, and a mean value of $m$ determined by least squares fitting to the experimental data was 0.21 .

Figure 7: Hardness change by rolling of $\mathrm{Zn}-5 \% \mathrm{Al}$ alloys. 


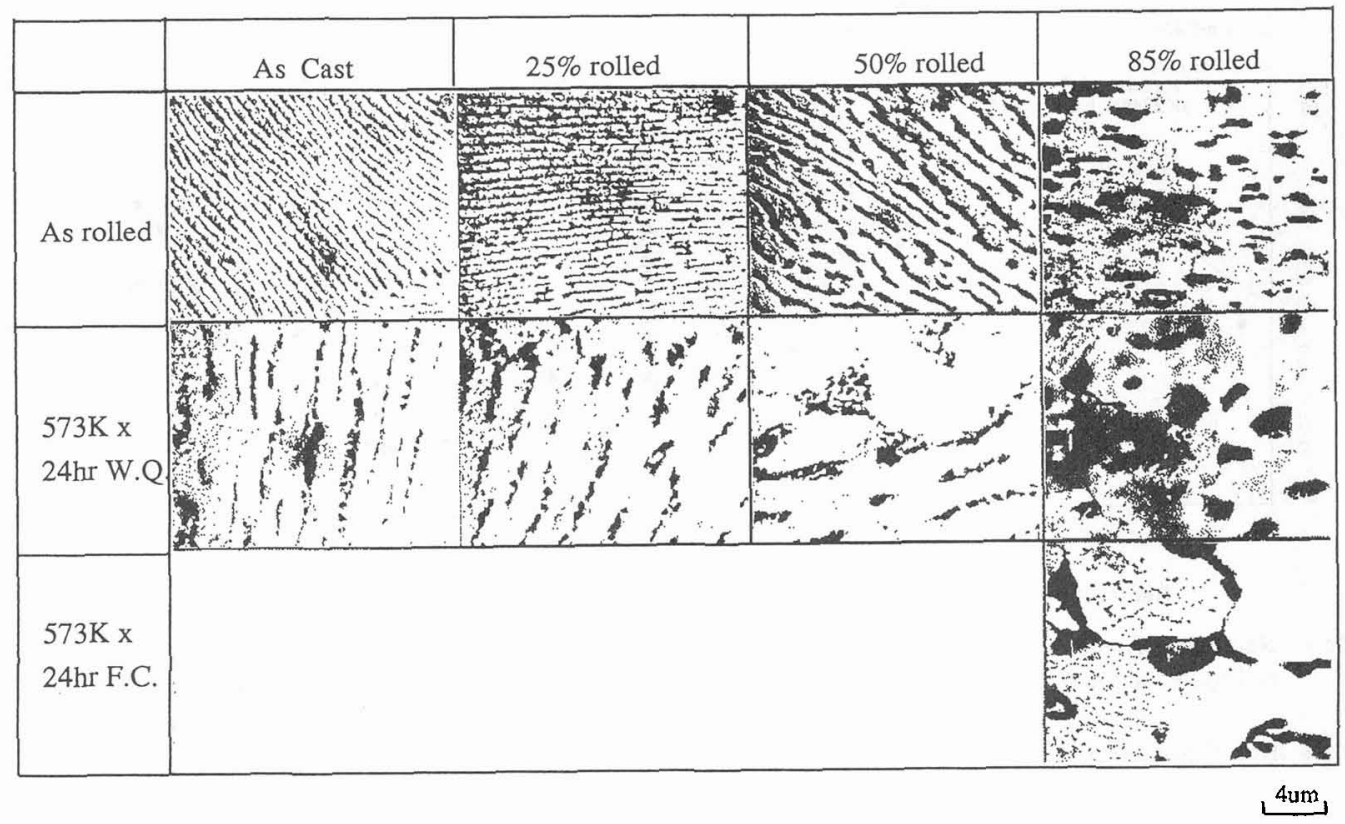

Figure 8: $\quad$ SEM micrographs of $\mathrm{Zn}-5 \% \mathrm{Al}$ alloys.

\section{Conclusions}

a) The grain sliding deformation by finer equiaxed $\alpha+\beta$ microstructure after large rolling reduction must be a major component for this damping

b) For cold rolled $\mathrm{Zn}-5 \% \mathrm{Al}$ alloys, hardness showed lower value and indicated significant change by varying rolling reduction by a work softening effect.

c) Grains after $85 \%$ cold rolling showed equiaxed features.

d) With an increase in the rolling reduction, a total amount of grain boundary of an equiaxed $\alpha+\beta$ is increased to resulted the increase in the damping.

e) The tensile strength strongly depends on the strain rate for $\mathrm{Zn}-5 \% \mathrm{Al}$ alloy, and indicated a maximum $m$ value of 0.35 .

\section{References}

[1] K. Nutall, J. Inst. Met., 99 (1971)pp.266-270

[2] A. E. W. Smith and G. A. Hare, J. Inst. Met., 101 (1970)pp.320-328

[3] W. A. Bachofen, I. R. Turner and D. H. Avery, Trans. ASM, 57 (1964)pp.980-990

[4] S. F. Radtke, Engineering Properties of Zinc Alloys., (International Lead Zinc Organization, Chap 1 , New York,1980)

[5] A. Ball and M. M. Hutchison, Metal Sci. J., 3 (1969)pp.1-5

[6] I. G. Ritchie and Z-L. Pan, Met. Trans., 22A (1991)pp.607-616

[7] I. G. Ritchie, Z-L. Pan and F. E. Goodwin, Met. Trans., 22A (1991)pp.617-623

[8] F. Li, W. T. Roberts and P. S. Bate, Acta. Mater., 44 (1996)pp.217-233

[9] C. M. Pacher, R. H. Jhonson and O. H. Sherby, Trans. AIME, 242 (1968)2485 